University of New Hampshire

University of New Hampshire Scholars' Repository

Civil and Environmental Engineering

Scholarship

Civil and Environmental Engineering

4-1-2017

\title{
Persistent organic pollutants in the Atlantic and southern oceans and oceanic atmosphere
}

\author{
Jenna L. Luek \\ University of New Hampshire, Durham, Jenna.Luek@unh.edu \\ Rebecca M. Dickhut \\ College of William and Mary \\ Michele A. Cochran \\ College of William and Mary \\ Renee L. Falconer \\ Colorado School of Mines \\ Henrik Kylin \\ Linköping University
}

Follow this and additional works at: https://scholars.unh.edu/civeng_facpub

\section{Comments}

This is an Accepted Manuscript of an article published by Elsevier in Science of The Total Environment in 2017, available online: https://dx.doi.org/10.1016/j.scitotenv.2016.12.189. This manuscript version is made available under the CC-BY-NC-ND 4.0 license http://creativecommons.org/licenses/by-nc-nd/4.0/

\section{Recommended Citation}

Luek, J.L., Dickhut, R.M., Cochran, M.A., Falconer, R.L., Kylin, H. 2017. Persistent organic pollutants in the Atlantic and Southern Oceans and oceanic atmosphere. Science of the Total Environment 583, 64-71.

This Article is brought to you for free and open access by the Civil and Environmental Engineering at University of New Hampshire Scholars' Repository. It has been accepted for inclusion in Civil and Environmental Engineering Scholarship by an authorized administrator of University of New Hampshire Scholars' Repository. For more information, please contact Scholarly.Communication@unh.edu. 
1 Persistent Organic Pollutants in the Atlantic and Southern Oceans and Oceanic

2 Atmosphere

3 Jenna L. Luek ${ }^{1,2}$, Rebecca M. Dickhut ${ }^{1 \wedge}$, Michele A. Cochran ${ }^{1}$, Renee L. Falconer ${ }^{3}$, Henrik

$4 \mathrm{Kylin}^{4,5}$

5 Science of the Total Environment, accepted manuscript. Published article can be found at:

6 http://dx.doi.org/10.1016/j.scitotenv.2016.12.189

7 (C) 2017. This manuscript version is made available under the CC-BY-NC-ND 4.0 license:

8 http://creativecommons.org/licenses/by-nc-nd/4.0/

$11{ }^{1}$ Virginia Institute of Marine Science, College of William and Mary, Gloucester Point, VA, USA

$12{ }^{2}$ Chesapeake Biological Laboratory, University of Maryland Center for Environmental Sciences,

13 Solomons, MD, USA

$14{ }^{3}$ Colorado School of Mines, Golden, CO, USA

$15{ }^{4}$ Department of Thematic Studies - Environmental Change, Linköping University, SE-

1658183 Linköping, Sweden

$17{ }^{5}$ Norwegian Institute for Air Research, Fram Centre, NO-9296 Tromsø, Norway

18 ^Author deceased

20 Corresponding Author Contact:

21 Jenna Luek

22 Chesapeake Biological Laboratory

23146 Williams Street 
$24 \quad$ PO Box 38

25 Solomons, MD, 20688

26 jluek88@gmail.com, 412-605-4898

27

28

\section{Highlights}

30 - Samples were collected between Sweden and Antarctica about R/V Oden in 2007

31 - Air and seawater samples were analyzed for persistent organic pollutants (POPs)

32 - Air and seawater POP concentrations were higher in the northern hemisphere

33 - Net fluxes for $\alpha-\mathrm{HCH}, \gamma-\mathrm{HCH}$, and Endosulfan were from air to seawater

34 - Ocean continues to act as a sink for legacy pesticides

35

36 


\section{Graphical Abstract}

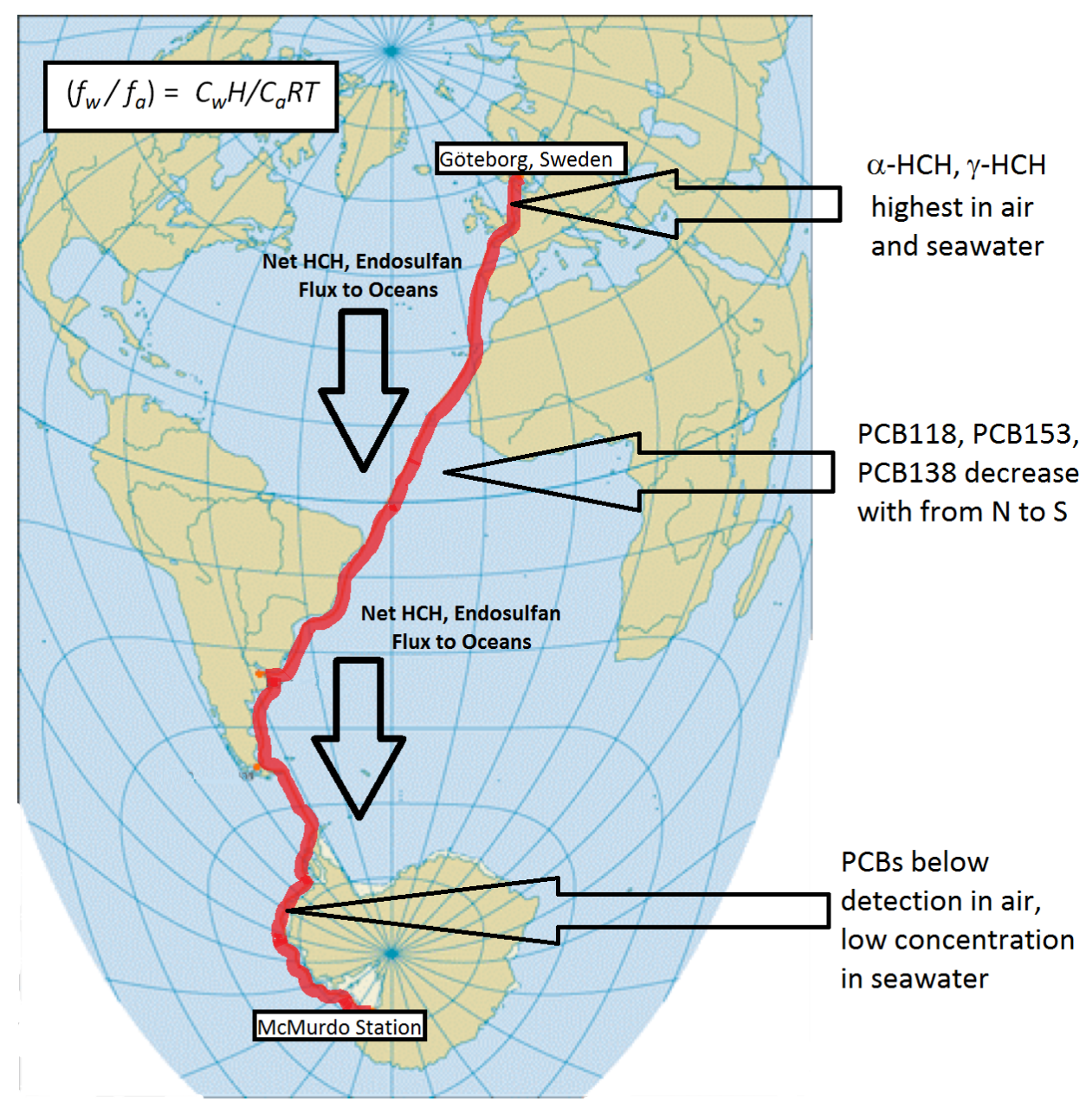




\section{Abstract}

Persistent organic pollutants (POPs) continue to cycle through the atmosphere and

40 hydrosphere despite banned or severely restricted usages. Global scale analyses of POPs are

41 challenging, but knowledge of the current distribution of these compounds is needed to

42 understand the movement and long-term consequences of their global use. In the current study,

43 air and seawater samples were collected Oct. 2007- Jan. 2008 aboard the Icebreaker Oden en

44 route from Göteborg, Sweden to McMurdo Station, Antarctica. Both air and surface seawater

45 samples consistently contained $\alpha$-hexachlorocyclohexane $(\alpha-\mathrm{HCH}), \gamma-\mathrm{HCH}$, hexachlorobenzene

46 (HCB), $\alpha$-Endosulfan, and polychlorinated biphenyls (PCBs). Sample concentrations for most

47 POPs in air were higher in the northern hemisphere with the exception of $\mathrm{HCB}$, which had high

48 gas phase concentrations in the northern and southern latitudes and low concentrations near the

49 equator. South Atlantic and Southern Ocean seawater has a high ratio of $\alpha-\mathrm{HCH}$ to $\gamma-\mathrm{HCH}$,

50 indicating persisting levels from technical grade sources. The Atlantic and Southern Ocean

51 continue to be net sinks for atmospheric $\alpha-, \gamma-\mathrm{HCH}$, and Endosulfan despite declining usage.

\section{Key words}

54 POPs, organochlorine pesticides, air-sea flux, hexachlorocyclohexane, Endosulfan 


\section{Introduction}

International regulation of persistent organic pollutants (POPs) is controlled by the Stockholm Convention of the United Nations Environment Programme (UNEP, 2016), which originally identified twelve pollutants to be monitored globally and their emissions to the environment reduced. This list included organochlorine pesticides including chlordane, hexachlorobenzene, and DDT, as well as polychlorinated biphenyls and polychlorinated dibenzop-dioxins and-furans. Additional chemicals identified as POPs continue to be added to this international treaty, including hexachlorocyclohexane (HCH) and Endosulfan (UNEP, 2016). POPs are distributed worldwide by various partitioning processes across interfaces between, e.g., air, water, and biota in aquatic and terrestrial environments (Jones and De Voogt, 1999; Wania and Mackay, 1996). Global scale studies of the atmospheric transport and air-sea exchange of POPs have had a major impact on our understanding of POP movement in the environment and the impact of POPs on remote locations (Dachs et al., 2002; Iwata et al., 1993; Pozo et al., 2009, 2006). According to the hypothesis of cold condensation, semi-volatile organic pollutants are constantly cycled from the gaseous phase in warmer latitudes to the cooler polar regions and deposited in aquatic and terrestrial environments where revolatilization is minimal (Wania and Mackay, 1996). Such chemicals have been found to accumulate in polar regions where they bioaccumulate in biota and may reach concentrations in top predators that potentially have adverse effects (Braathen et al., 2004; Brault et al., 2013; Goerke et al., 2004; Oskam et al., 2004; Sonne, 2010). Although substantial work has been done in the Arctic to monitor these compounds and their impacts, studies on POP distribution and movement in the Southern hemisphere and particularly the Antarctic have been much more limited. Changes in polar regions are of particular interest as legacy use compounds may be released to the aquatic 
78 environment and atmosphere during the melting of ice sheets and general warming (Cabrerizo et

79 al., 2013; Cincinelli et al., 2016; Geisz et al., 2008; Goerke et al., 2004).

Information on air-sea fluxes of individual POPs is important to understand if a particular

81 area of the sea acts as a sink or a source, which, in turn, is essential for the understanding of the

82 global distribution and environmental fate of these contaminants. Without environmental

83 distribution and fate information, environmental risks cannot be estimated. A particular

84 advantage of long geographical transects is that information from a wide range of environmental

85 conditions and distances from anthropogenic sources can be collected.

86 This study took place during the expedition "Oden Southern Ocean 2007-2008” (OSO

87 07-08). The objective was to collect information on the distribution and air-sea fluxes of several

88 POPs in a north-south transect of the Atlantic Ocean and a west-east transect in the Southern

89 Ocean between the Western Antarctic Peninsula and the Ross Sea.

90

\section{Methods}

92 Sample Collection. Air and surface seawater samples were collected aboard the Swedish

93 Icebreaker Oden on a transect between Göteborg, Sweden and McMurdo Station, Antarctica

94 from 23 October through 4 January 2008 (Figure 1, Table S1). Samples were analyzed for 26

95 current and past-use organochlorine pesticides and 21 polychlorinated biphenyls (PCBs) using

96 gas chromatography combined with mass spectrometry (Table S2). Gas and dissolved phase

97 concentrations were then used to calculate air-sea fluxes. 


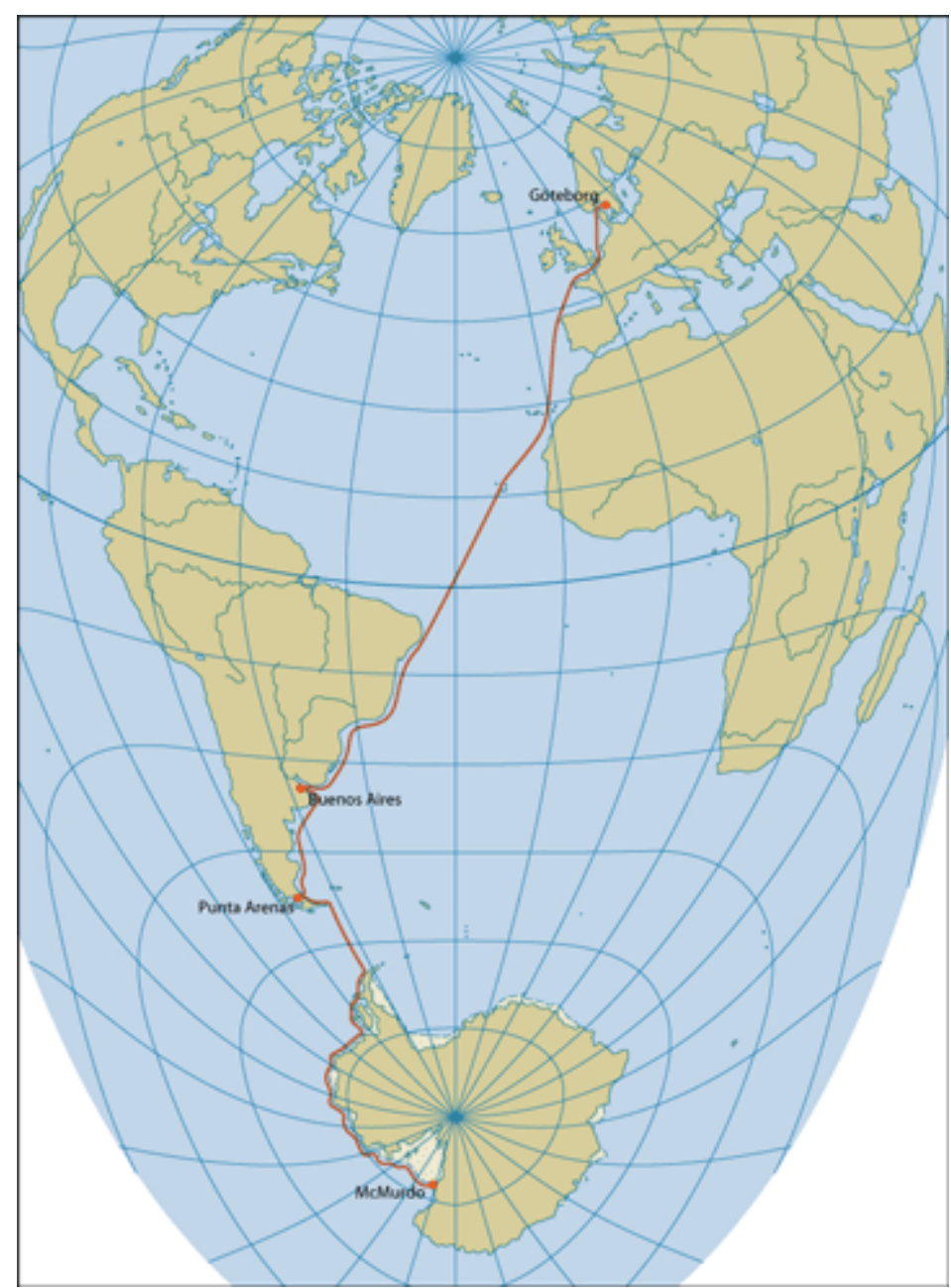

$99 \quad$ Figure 1. Cruise track for the Swedish Icebreaker Oden, Oct. 2007 - Jan. 2008.

101 Air samples were collected using two high volume samplers consisting of $150 \mathrm{~mm}$ diameter

102 glass fiber filters (GFFs) to collect aerosol samples and two polyurethane foam (PUF) plugs (8

$103 \mathrm{~cm}$ diameter $\mathrm{x} 7.6 \mathrm{~cm}$ ) to collect gas phase samples of approximately $500 \mathrm{~m}^{3}$. The air samplers

104 were deployed in front of Deck 5, approximately $18 \mathrm{~m}$ above the sea surface with the bulk of the

105 bridge shielding the samplers from the stack and, except during storms, out of the sea spray.

106 Sampling took place only while under way, but regardless of wind direction. Prior to use, the

107 GFFs were baked for $4 \mathrm{~h}$ at $400{ }^{\circ} \mathrm{C}$ and the PUFs Soxhlet extracted with acetone and petroleum 
108 ether (24 h each). GFFs were stored in envelopes of aluminum foil baked at $400{ }^{\circ} \mathrm{C}$ and PUF

109 plugs were stored in precleaned glass jars, both at $-20^{\circ} \mathrm{C}$ after sampling, until extraction.

110 To increase sample volume, some PUF gas phase samples were composited such that

111 sample volumes ranged from $\sim 500-1400 \mathrm{~m}^{3}$ for Atlantic samples and $\sim 600-2000 \mathrm{~m}^{3}$ for Antarctic

112 samples. Only Atlantic aerosol samples were analyzed as part of this study and were also

113 composited prior to extraction to increase sample volumes $\left(3500-6500 \mathrm{~m}^{3}\right)$. Antarctic aerosol

114 analyses have been reported previously (Dickhut et al., 2012). A surrogate standard mixture of

115 perdeuterated $\alpha$-hexachlorocyclohexane $\left(\mathrm{d}_{6}-\alpha-\mathrm{HCH}\right)$ and PCB 204 was added and PUF plugs

116 were Soxhlet extracted with acetone and petroleum ether ( $24 \mathrm{~h}$ each). Anhydrous sodium sulfate

117 was added to the sample extracts to remove residual water, and extracts were reduced to $10 \mathrm{~mL}$

118 using rotary evaporation (Buchi) and/or a Turbovap II (Zymark), exchanged into hexane, and

119 further reduced to $3 \mathrm{~mL}$ using a gentle stream of ultra-high purity $\mathrm{N}_{2}$. Aerosol extracts and

120 approximately half the gas phase extracts were acid treated using concentrated sulfuric acid. The

121 sample extracts were then cleaned up using silica column chromatography (Chiuchiolo et al.,

122 2004), and an internal standard $\left(\mathrm{d}_{6}-\gamma-\mathrm{HCH}\right)$ was added prior to volume reduction to $\sim 100 \mu \mathrm{l}$

123 using ultra high purity $\mathrm{N}_{2}$.

124 Seawater samples were collected via a direct inlet line from the bottom of the ship (app. 8

$125 \mathrm{~m}$ depth) into the laboratory. The entire inlet system was made of acid resistant stainless steel

126 with the exception of PTFE pump impellers. Large volume seawater samples $(\sim 110 \mathrm{~L}$ for

127 Atlantic Ocean and 150-160 L for Southern Ocean) were collected in steel holding tanks and

128 treated according to Dickhut et al., 2005. The water was extracted by passing through a column

129 (35 cm x $25 \mathrm{~mm}$ i.d.) of Amberlite XAD-2 resin (Sulpeco, Bellefonte, PA). The XAD-2 resin

130 columns were stored at $4{ }^{\circ} \mathrm{C}$ until extraction. For analyses, the XAD-2 resin was Soxhlet 
131 extracted with acetone and hexane ( $24 \mathrm{~h}$ each) after the addition of the surrogate standard

132 mixture described above. The acetone fractions were back-extracted using hexane and hexane-

133 extracted water three times via agitation for three minutes, and the resulting hexane was

134 combined with the hexane extract and reduced in volume by rotary evaporation. The hexane

135 extracts were then cleaned and analyzed as described above.

136 Quantification. Samples were analyzed on a Hewlett-Packard 6890 Gas Chromatograph

137 with a 5973 Mass-Selective Detector in negative chemical ionization mode using a J\&W DB-

138 35MS capillary column $(30 \mathrm{~m} \times 0.25 \mathrm{~mm}$ i.d., $0.25 \mu \mathrm{m}$ film thickness $)$ and selective ion

139 monitoring. Method parameters for analysis were as follows: $70{ }^{\circ} \mathrm{C}$ initial hold time of $1 \mathrm{~min}$;

$140 \quad 70-150{ }^{\circ} \mathrm{C}$ at $20^{\circ} \mathrm{C} \min ^{-1} ; 150-280{ }^{\circ} \mathrm{C}$ at $4{ }^{\circ} \mathrm{C} \min ^{-1}$, hold for $15 \mathrm{~min} ; 280-295{ }^{\circ} \mathrm{C}$ at $5{ }^{\circ} \mathrm{C} \mathrm{min}{ }^{-1}$,

141 hold for $2 \mathrm{~min}$; source temperature $150{ }^{\circ} \mathrm{C}$. The carrier gas for both methods was helium at 1.0

$142 \mathrm{~mL} \mathrm{~min}^{-1}$ with a velocity of $39 \mathrm{~cm} \mathrm{~s}^{-1}$ (Chiuchiolo et al., 2004).

143 Quality Assurance and Quality Control. Quality control procedures included the

144 collection and analysis of laboratory and field blanks, selected duplicate samples, and

145 breakthrough on PUF plugs, non-sequential sample extraction ordering, quantitation of surrogate 146 standard and internal standard recoveries, and the use of a conservative method detection limit.

147 Laboratory and field blanks were collected and analyzed as quality control procedures.

148 One laboratory blank of baked GFF filters was extracted alongside composite particulate filters

149 (1 laboratory blank to eight samples), as were two laboratory blanks of cleaned PUF not taken in

150 the field. Paired air and seawater field blanks were collected across the Atlantic leg every seven

151 samples (three total), and four air field blanks (30s on high volume air sampler) and two

152 seawater field blanks were collected during the Antarctic leg. Field duplicate Antarctic PUF

153 samples were collected, but most were combined to increase sample volume. Two PUF field 
154 duplicates were analyzed separately, and for one pair analytes agree well (most NQ, $\gamma$-HCH 0.99

$155 \mathrm{pg} \mathrm{m}^{-3}$ vs. $0.83 \mathrm{pg} \mathrm{m}^{-3}$; HCB $23 \mathrm{pg} \mathrm{m}^{-3}$ vs. $24 \mathrm{pg} \mathrm{m}^{-3}$ ). For the second pair, the values are similar

156 for $\alpha-\mathrm{HCH}$ - NQ (MDL $0.11 \mathrm{pg} \mathrm{m}^{-3}$ ) vs. $0.12 \mathrm{pg} \mathrm{m}^{-3}$, but $\gamma-\mathrm{HCH}$ and HCB concentrations were

157 not similar $\left(\gamma-\mathrm{HCH} 1.9 \mathrm{pg} \mathrm{m}^{-3}\right.$ vs. $<$ MDL; HCB $99 \mathrm{pg} \mathrm{m}^{-3}$ vs. $\left.20 \mathrm{pg} \mathrm{m}^{-3}\right)$. Two duplicate seawater

158 samples were collected during the Atlantic leg, but unfortunately one of these had no surrogate

159 standard recovery so analytes could not be quantified.

160 Sample extractions were performed in a non-sequential order to prevent laboratory

161 changes over time from imitating geographic trends, and at least every other set of four soxhlet

162 extractions included either a laboratory or field blank control sample. The front and back PUF

163 plugs were analyzed and quantified separately to determine the breakthrough of individual

164 analytes. The average breakthrough of $\alpha-\mathrm{HCH}$ and $\gamma-\mathrm{HCH}$ from the front to the back PUF was

$16521 \pm 18$ and $24 \pm 11 \%$, respectively. Breakthrough for hexachlorobenzene (HCB) was highest

$166(33 \pm 8 \%)$ and $\alpha$-Endosulfan was lowest $(13 \pm 11 \%)$. As expected, breakthrough was greater for

167 lower molecular weight compounds and more volatile compounds. Breakthrough was also higher

168 at lower latitudes and warmer temperatures compared to higher latitudes, which should be

169 considered when sampling over a wide range of latitudes or during a variety of seasons. The PUF

170 had also been used once prior to sampling, which may have degraded its ability to collect.

171 Alternatively, a longer PUF column length may be necessary to improve the extraction efficiency

172 for more volatile compounds.

173 Surrogate standard recovery of $d_{6}-\alpha-H C H$ in gas phase air samples was $65 \pm 6 \%$ and

$17481 \pm 8 \%$ for PCB 204 (average \pm confidence interval, $\alpha=0.05$ ). Surrogate standard recovery of

175 aerosol samples was $89 \pm 33 \%$ for PCB 204. Surrogate standard recoveries in seawater samples 
176 were $85 \pm 4 \%$ for $\mathrm{d}_{6}-\alpha-\mathrm{HCH}$ and $115 \pm 5 \%$ for PCB 204 . Reported sample concentrations are not

177 corrected for surrogate standard recoveries.

178 Method detection limits (MDLs) were conservatively calculated as three times the

179 average field and lab amount in pg and divided by the average sample volume in $\mathrm{m}^{3}$ or $\mathrm{L}$

180 (Dickhut et al., 2012). In cases where no quantifiable peak was identified for a given compound

181 in any blanks, the MDL was set to $0.05 \mathrm{pg} \mathrm{m}^{-3}$ (air) and $0.13 \mathrm{pg} \mathrm{L}^{-1}$ (seawater) as these were on

182 the low end of calculated MDLs for individual analytes.

183

\section{Results and Discussion}

The most frequently identified compounds in the gas phase and seawater were $\alpha-\mathrm{HCH}, \gamma-$

$186 \mathrm{HCH}, \mathrm{HCB}, \alpha$-Endosulfan, heptachlor, and PCB congeners 118, 138, 153, 180, and 187 (Figure

187 2, Figure 3, Table S3, Table S4). $\alpha-\mathrm{HCH}, \boldsymbol{\gamma}-\mathrm{HCH}, \mathrm{HCB}, \alpha$-Endosulfan, and heptachlor were

188 also detected in the eight composite aerosol samples (Figure S1, Table S5). High concentrations

189 of heptachlor were identified in both aerosol and gas phase blanks and are therefore not reported.

190 In samples collected while the ship was breaking ice, with frequent backing up and ramming, a

191 grey color was observed on the filters indicating influence from the smoke stack. But even when

192 ship contamination was expected (e.g., Dec. 29-Jan. 1), most compounds were not quantifiable in

193 field blanks. Thus, although ship influence is possible, it is not expected to contribute to the

194 specific analytes or influence the interpretation of the results with the exception of Antarctic

195 HCB concentrations.

Hexachlorocyclohexane. $\alpha-\mathrm{HCH}$ and $\gamma-\mathrm{HCH}$ concentrations in gas phase samples 
$199 \mathrm{pg} \mathrm{\textrm {m } ^ { - 3 }}$, respectively. $\alpha-\mathrm{HCH}$ and $\gamma-\mathrm{HCH}$ concentrations in aerosol samples were low and close to

200 MDLs (0.06 $\mathrm{pg} \mathrm{m}^{-3}$ and $0.10 \mathrm{pg} \mathrm{m}^{-3}$, respectively), with only $\gamma$-HCH detected above the method

201 detection limit at one site. The highest concentrations of gas phase HCHs were found in the

202 northern hemisphere with a sharp drop off below the equator (Figure 2). HCHs were

203 significantly higher (Student's t-test, $\mathrm{p}<0.01$ ) in the northern versus southern hemisphere. The

204 highest concentrations of both isomers were observed off the Western European coastline (45

$\left.205 \mathrm{~N}, 8^{\circ} \mathrm{W}\right)$. In the Southern hemisphere, $\alpha-\mathrm{HCH}$ consistently declined southward but $\gamma-\mathrm{HCH}$

206 concentrations increased slightly near 50S, potentially indicating recent South American use.

207 These values are consistent with the spatial and temporal patterns reported over the past two

208 decades, including Eastern Atlantic transects in 1999 and 2008 (Lakaschus et al., 2002; Xie et

209 al., 2011). Since 1987, a clear decline of nearly an order of magnitude has been observed in HCH

210 concentrations across this transect (Xie et al., 2011). 

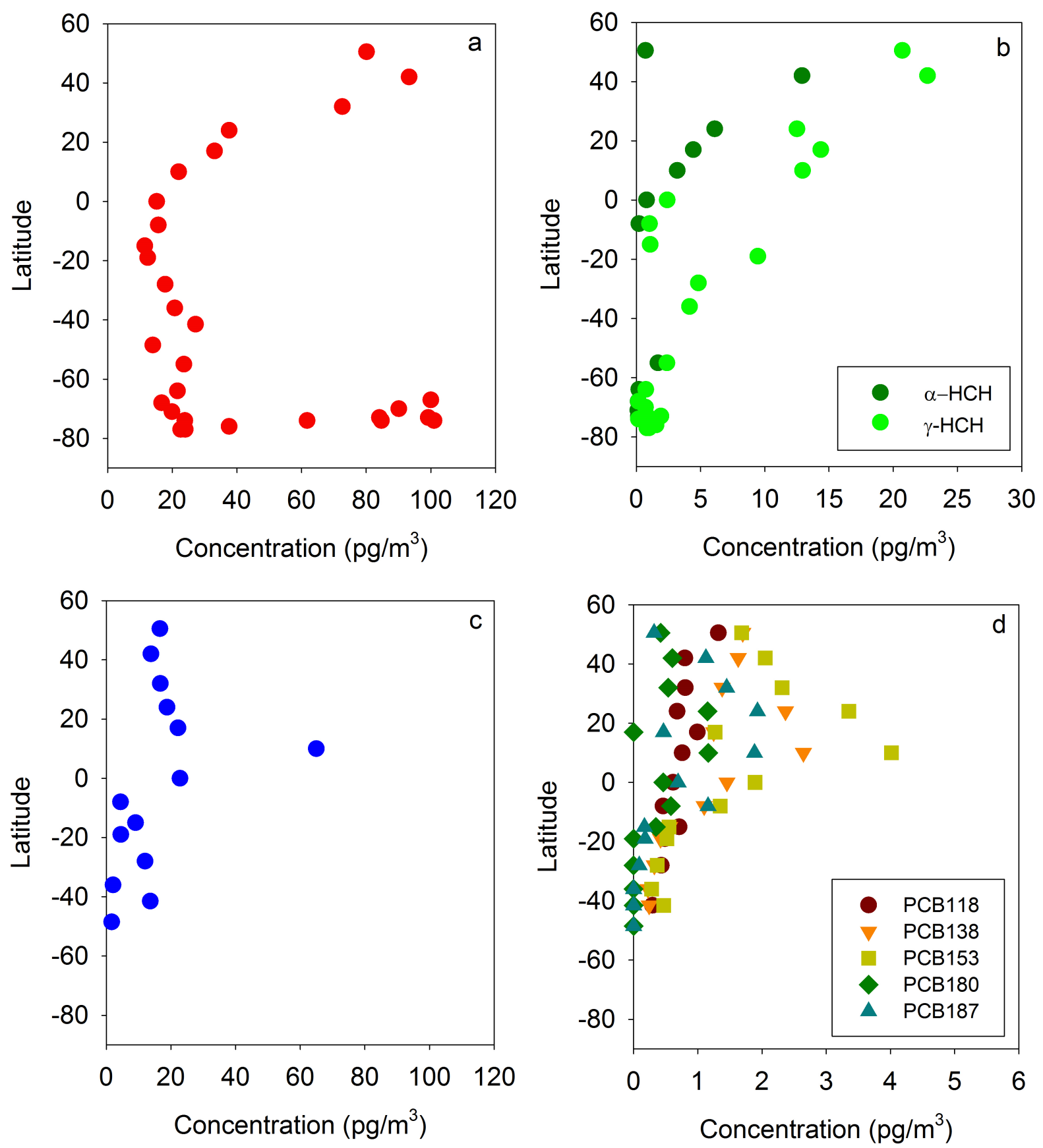

212 Figure 2. Gas-phase air concentrations of a) hexachlorobenzene b) hexachlorocyclohexanes c)

213 Endosulfan I d) polychlorinated biphenyls in the Atlantic and Southern Oceans, Oct. 2007-Jan.

214 2008. $<$ MDLs and NQ not shown. 

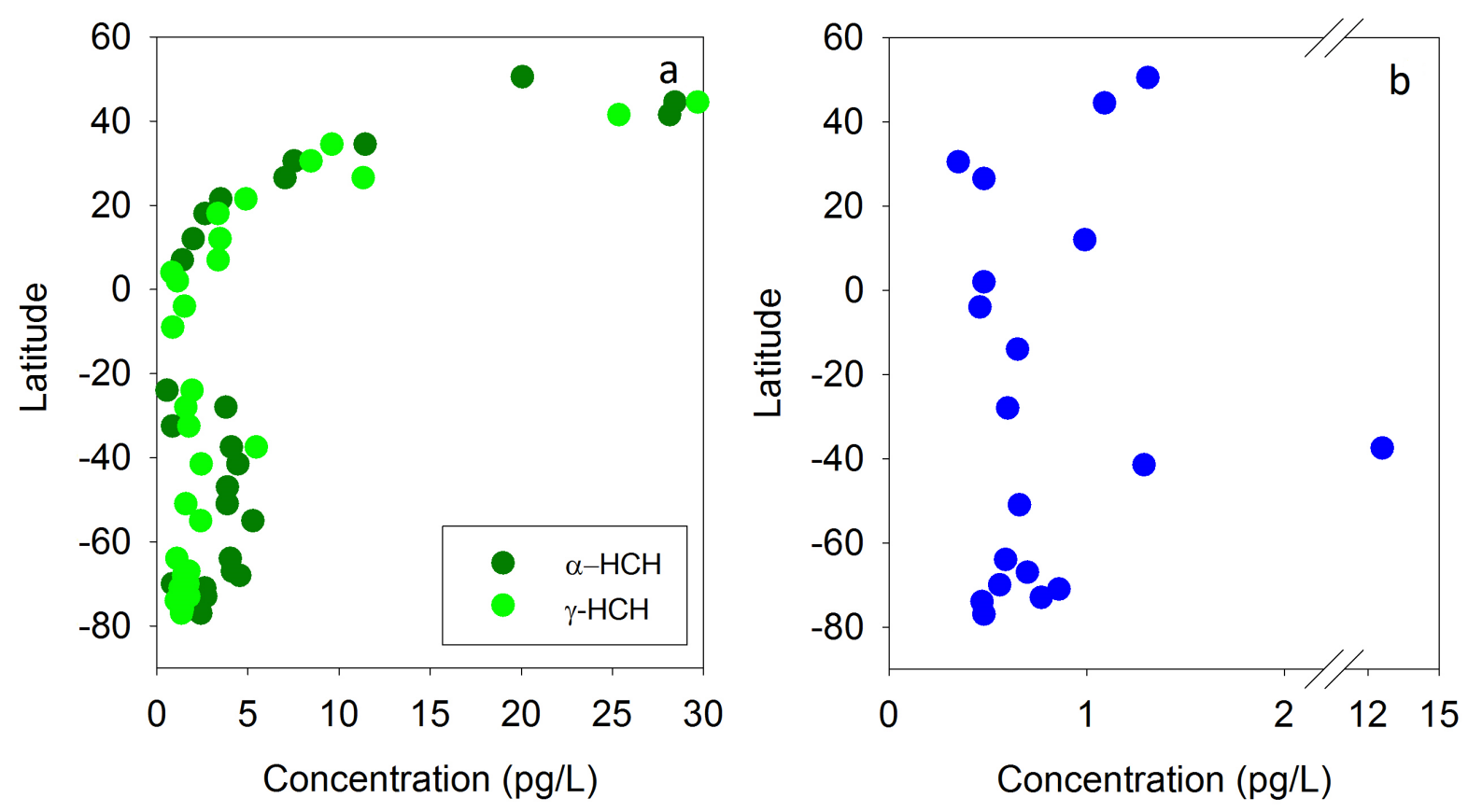

216 Figure 3. Seawater dissolved phase concentrations of a) hexachlorocyclohexanes *not showing

217 point at $50.5 \mathrm{~N}, 77 \mathrm{pg} \mathrm{L}^{-1}$ for scaling reasons b) Endosulfan I in the Atlantic and Southern

218 Oceans, Oct. 2007-Jan. 2008. Samples <MDLs and NQ not shown.

Gas phase samples collected at latitudes below $60^{\circ} \mathrm{S}$ in the present study had

221 concentrations of $\alpha-\mathrm{HCH}$ and $\gamma-\mathrm{HCH}$ that ranged from below MDLs to 0.99 and $1.9 \mathrm{pg} \mathrm{m}^{-3}$,

222 respectively. These are similar to levels reported in 2001- 2002 in the Western Antarctic

223 Peninsula (0.05-0.52 $\mathrm{pg} \mathrm{m}^{-3}$ for $\alpha-\mathrm{HCH}$, and 0.06-2.4 $\mathrm{pg} \mathrm{m}^{-3}$ for $\gamma-\mathrm{HCH}$ ) (Dickhut et al., 2005).

224 Antarctic atmospheric $\alpha$ - and $\gamma-\mathrm{HCH}$ concentrations measured in this study are consistent with

225 declines seen over the past twenty-five years (Bidleman et al., 1993; Dickhut et al., 2005;

226 Jantunen et al., 2004; Tanabe et al., 1983). Given that HCHs have been shown to have half-lives

227 of $\sim 3$ years in Antarctic air (Dickhut et al., 2005), the similar levels measured in 2007-2008

228 compared to 2001-2001 may indicate that current sources, such as continued agricultural use, 
229 may contribute $\mathrm{HCHs}$ to the Southern Ocean atmosphere. Alternatively, if agricultural use has

230 declined, a possible source of $\mathrm{HCHs}$ is volatilization from the western Antarctic ice sheet, which

231 has been shown to be a source of other legacy use pesticides to the aquatic environment

232 (Cincinelli et al., 2016; Geisz et al., 2008).

233 The ratios of $\alpha-\mathrm{HCH}$ to $\gamma-\mathrm{HCH}$ in the gas phase were computed to investigate the

234 presence of technical grade $\mathrm{HCH}$ versus the purer lindane $(\gamma-\mathrm{HCH})$ in samples where both

235 isomers were above method detection limits; a ratio greater than one represents higher amounts

$236 \alpha-\mathrm{HCH}$ isomer associated with technical grade $\mathrm{HCH}$ that has been phased out (Figure S2).

237 Atmospheric $\alpha-\mathrm{HCH}$ concentrations are lower than $\gamma-\mathrm{HCH}$ concentrations across the Atlantic

238 transect, which is consistent with a global reduction in technical HCH usage (Li et al., 1998), but

239 may also imply continued sources of current use $\gamma-\mathrm{HCH}$. $\alpha-\mathrm{HCH}$ appears to be longer lived in

240 the atmosphere ( $\mathrm{t}_{1 / 2}$ of 120 vs. $96 \mathrm{~d}$ ) (Harner et al., 1999; Li et al., 2004), but $\gamma$-HCH may be

241 degraded to $\alpha-\mathrm{HCH}$ (Walker et al., 1999) complicating the meaning of this ratio.

242 Seawater $\alpha-$ and $\gamma-\mathrm{HCH}$ concentrations ranged from below MDLs to 28 and $77 \mathrm{pg} \mathrm{L}^{-1}$,

243 respectively (MDL $\alpha-\mathrm{HCH}=0.13 \mathrm{pg} \mathrm{L}^{-1}, \gamma-\mathrm{HCH}=0.13 \mathrm{pg} \mathrm{L}^{-1}$ ) (Figure 3, Table S4). Similar to

$244 \mathrm{HCHs}$ in air, a spatial trend with significantly higher concentrations in the northern hemisphere

245 and lower concentrations in the southern hemisphere was observed (Student's t-test, $\mathrm{p}<0.01$ ).

246 This latitudinal trend has been observed over the past two decades by several researchers (Harner

247 et al., 1999, 1999; Iwata et al., 1993; Lakaschus et al., 2002; Schreitmueller and Ballschmiter,

248 1995; Xie et al., 2011). Current concentrations also followed a temporal decline noted by

249 Lakaschus et al., (2002). A 2008 Eastern Atlantic sampling cruise also observed a slight increase

250 in $\alpha-\mathrm{HCH}$ near 50S (Xie et al., 2011). This may be caused by regional technical HCH use (Pozo 
251 et al., 2006) or by the isomerization of $\gamma-\mathrm{HCH}$ to $\alpha-\mathrm{HCH}$ in the environment (Walker et al., 252 1999).

A somewhat bimodal distribution was observed in the ratios of $\alpha-\mathrm{HCH}$ to $\gamma-\mathrm{HCH}$ in

254 seawater samples (Figure S2), where the northern and southern latitudes had higher ratios and

255 tropical latitudes had lower ratios (or were not calculated due to non-detection of one of the two

256 isomers). However, the southern latitudes had 3.5 times as much $\alpha-\mathrm{HCH}$ as $\gamma-\mathrm{HCH}$, where as

257 northern latitudes hover at or below 1. Consistently higher $\alpha$ - to $\gamma$-HCH ratios in Antarctic

258 seawater versus air indicate that $\alpha-\mathrm{HCH}$ may be longer lived in the seawater environment than $\gamma$ -

$259 \mathrm{HCH}$, or represent an older pool of $\mathrm{HCH}$ dominated by technical grade containing $\alpha-\mathrm{HCH}$. The

260 apparent half-life of $\mathrm{\Sigma HCHs}$ in the Antarctic seawater environment has previously been

261 estimated as 2 y and $3.4 \mathrm{y}$ in two separate studies (Chiuchiolo et al., 2004; Galbán-Malagón et

262 al., 2013), which is similar to half-lives reported Antarctic air (3 y) (Dickhut et al., 2005).

263 However, much longer half-lives of 5.9 years and 23.1 years for the (+) and (-) enantiomers of $\alpha-$

$264 \mathrm{HCH}$ and 18.8 years for $\gamma$-HCH were reported in the Eastern Arctic Ocean during a 1996 cruise

265 (Harner et al., 1999). It is unclear why such a high ratio of $\alpha-\mathrm{HCH}$ persists in Southern Ocean

266 seawater and not in the overlying atmosphere, but is likely driven by current and historical usage

267 patterns as well as differing degradation rates and isomerization from $\gamma-\mathrm{HCH}$ to $\alpha-\mathrm{HCH}$ (Harner

268 et al., 1999; Li et al., 1998; Walker et al., 1999).

Hexachlorobenzene. HCB was ubiquitous in gas phase air samples with concentrations

271 ranging from 12 to $100 \mathrm{pg} \mathrm{m}^{-3}\left(\mathrm{MDL}=1.3 \mathrm{pg} \mathrm{m}^{-3}\right)$. $\mathrm{HCB}$ in aerosol samples $(\mathrm{MDL}=0.21 \mathrm{pg}$

$272 \mathrm{~m}^{-3}$ ) was frequently below detection limits with only two samples above the MDL. The highest

273 concentrations of HCB in the gas phase were observed in the northern Atlantic and Antarctic air 
274 while lower concentrations were measured in tropical and South Atlantic air. A comparison of

275 front and back PUF indicated high levels of HCB breakthrough in the Atlantic samples that were

276 collected at temperatures greater than $20^{\circ} \mathrm{C}(54 \pm 3 \%)$. In a 2009 Atlantic transect (N-S and E-

277 W), HCB concentrations were lowest near the equator although concentrations were nearly an

278 order of magnitude lower than reported here for most samples (Lohmann et al., 2012). However,

279 breakthrough information was not reported for these samples.

280 Southern Ocean HCB concentrations ranged from 17-100 $\mathrm{pg} \mathrm{m}^{-3}$ with no discernible

281 pattern over the concentration range, slightly higher than the range reported during a $2008-2009$

282 sampling expedition along the Western Antarctic peninsula (Galbán-Malagón et al., 2013a).

283 However, air mass back trajectories (Stein et al., 2015) did not indicate unique air masses for

284 high versus low concentration sampling periods (Figure S3, Table S6). Lab and field blanks

285 extracted and analyzed at the same time are similar and do not indicate a contamination event

286 during the high HCB concentration sample extractions. It is noteworthy, however, that the high

287 concentration events all are from the highest latitudes. This opens up for two explanations: 1)

288 emission of legacy HCB from the melting continental or shelf ice as suggested by (Geisz et al.,

289 2008) or, 2) contamination from the ship during icebreaking. The second explanation is, perhaps,

290 the more likely, as release of legacy POPs from melting glaciers would probably also lead to

291 locally increased air concentrations of, e.g., $\mathrm{HCHs}$, which is not observed. Elevated air

292 concentrations of HCB during icebreaking have not been observed during previous expeditions

293 with Oden, but in this case the bunker fuel was from a different source than normally used.

294 A further indication that it might be conditions during icebreaking that caused the high

295 concentrations of $\mathrm{HCB}$ at high latitudes is that in one case, a duplicate pair collected from the

296 same time and location had vastly different concentrations (20 vs. $\left.99 \mathrm{pg} \mathrm{m}^{-3}\right)$. With a strong side 
297 wind, it is likely that one of the air samplers picked up more of a locally produced contamination 298 than the other.

An autumn 2001 sampling cruise found atmospheric HCB levels in air that averaged 19

300 ( \pm 7.6$) \mathrm{pg} \mathrm{m}^{-3}$ on the Western Antarctic Peninsula north of $68^{\circ} \mathrm{S}$ (Dickhut et al., 2005). More

301 recently, the Norwegian Troll long term monitoring station in Dronning Maud Land, [Antarctica]

302 observed consistent $22 \mathrm{pg} \mathrm{m}^{-3} \mathrm{HCB}$ concentrations from 2007-2010, with an austral winter peak

303 (Kallenborn et al., 2013). The highest recent Antarctic HCB measurements (2008-2009) peaked

304 at $49.7 \mathrm{pg} \mathrm{m}^{-3}$ (Galbán-Malagón et al., 2013a) along the Western Antarctic Peninsula, but are not

305 as high as the highest HCB concentrations observed in this study.

A high HCB MDL was calculated for the seawater samples $\left(8.0 \mathrm{pg} \mathrm{L}^{-1}\right)$ and therefore

307 HCB was only above the MDL in one seawater sample collected at $50^{\circ} \mathrm{N}\left(11 \mathrm{pg} \mathrm{\textrm {L } ^ { - 1 }}\right)$. In

308 previous transects, $\mathrm{HCB}$ has only been observed in seawater at concentrations of $1 \mathrm{pg} \mathrm{L}^{-1}$ or less

309 (Lohmann et al., 2012, Zhang and Lohmann, 2010, Galbán-Malagón et al., 2013).

Endosulfan. Endosulfan ( $\alpha$-Endosulfan) concentrations in gas phase air samples ranged

312 from below the MDL $\left(0.21 \mathrm{pg} \mathrm{m}^{-3}\right)$ to $65 \mathrm{pg} \mathrm{m}^{-3}$ with significantly higher levels in the northern

313 versus southern hemisphere (Student's t-test, $\mathrm{p}=0.03)$. Endosulfan in aerosol samples $(\mathrm{MDL}=$

$3140.03 \mathrm{pg} \mathrm{m}^{-3}$ ) was frequently below detection limits with only three samples above the MDL.

315 High Endosulfan gas phase concentrations were observed off the West African coast, where an

316 air mass back trajectory indicated air of continental origin. Inland passive air sampling in West

317 Africa observed extremely high levels of Endosulfan ( $\operatorname{sum}$ of $\alpha-, \beta-$, and $-\mathrm{SO}_{4}$ ) in passive air

318 sampling ( 2400 $\mathrm{pg} \mathrm{m}^{-3}$ in 2004-2005) indicating that these high levels are likely due to regional

319 agricultural applications (Pozo et al., 2009, 2006). Although atmospheric Endosulfan peaked off 
320 the African coast, seawater concentrations did not, yielding further support that atmospheric

321 conditions were influenced by a continental air mass rather than long-term equilibration with

322 seawater and the overlying air masses. Although banned in more than fifty countries, Endosulfan

323 continues to be used on major crops including coffee, soy, cotton, and tobacco, but will be

324 phased out over the next decade due to inclusion on the Stockholm Convention (UNEP, 2016).

325 In the Antarctic atmosphere, low Endosulfan levels (0.2-0.8 $\mathrm{pg} \mathrm{m}^{-3}$ ) were detected with only

326 three of thirteen samples above the method detection limit. On King George Island, Endosulfan

327 was found to be the most prevalent and abundant organochlorine pesticide (average $27 \mathrm{pg} / \mathrm{m}^{3}$ )

328 during multi-year monitoring (2005-2007) (Baek et al., 2011). Prior to that study, Endosulfan

329 had not been detected in Antarctic air, but may be because Endosulfan was rarely included as an

330 analytes (Pozo et al., 2006). Based on these results and similar Arctic findings (Weber et al.,

331 2010), Baek and colleagues suggested that Endosulfan is extensively transported to polar regions

332 (Baek et al., 2011). However, air mass back trajectories in the current study indicate air of

333 oceanic origin, potentially explaining why low of Endosulfan was observed in the present study

334 rather than at levels similar to King George Island which is more likely influenced by direct

335 South American air masses.

336 Seawater Endosulfan concentrations (Figure 3) were consistently low and showed no

337 clear latitudinal trends. No clear hemispheric difference is consistent with approximately

338 equivalent northern and southern hemisphere applications and continued Endosulfan use (Weber

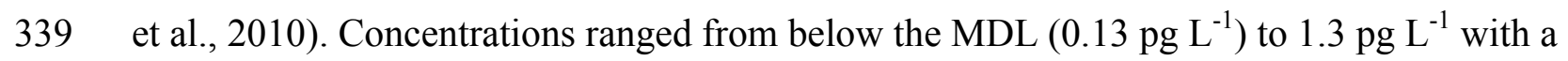

340 single outlier of $13 \mathrm{pg} \mathrm{L}^{-1}$ measured at $37^{\circ} \mathrm{S}$. This outlier was collected near shore in the Rio de

341 la Plata estuary, the second largest drainage basin in South America, draining large agricultural

342 and urban regions where Endosulfan have been used recently and continue to persist at high 
343 concentrations in agricultural stream beds (Hunt et al., 2016). Endosulfan concentrations in

344 seawater have not been previously reported along an Atlantic transect or in the Antarctic. Arctic

345 sampling has shown low Endosulfan concentrations (mean $2.3 \mathrm{pg} \mathrm{L}^{-1}$ ) similar in magnitude to

346 these findings (Weber et al., 2010).

Polychlorinated Biphenyls. Twenty different PCB congeners were analyzed in the gas

349 phase samples, but only congeners $118,138,153,180$, and 187 were consistently detected

350 (Figure 2). PCBs were quantified in two aerosol samples but all were below MDLs. Gas phase

351 concentrations were highest in the northern hemisphere and were nearly undetectable in the air

352 over the South Atlantic and Southern Ocean (MDLs ranged from $0.05 \mathrm{pg} \mathrm{m}^{-3}$ to $0.26 \mathrm{pg} \mathrm{m}^{-3}$ for

353 individual congeners). In an Atlantic sampling cruise in 2008, PCBs 153 and 180 were reported

354 to have concentrations similar to those observed for the tropical Atlantic (Lohmann et al., 2012).

355 In the present study, PCB153 and PCB180 levels were approximately twice those reported by

356 Lohmann north of the equator, likely because sampling occurred on the Western Atlantic

357 (present study) versus the Eastern Atlantic (Lohmann et al., 2012). Previous studies have shown

358 high atmospheric PCB concentrations in these coastal waters (including those identified here,

359 PCB118, 138, 153, and 180), with mass back trajectories indicative of a known West Africa

360 source (Gioia et al., 2011, 2008).

361 Four of the five PCB congeners consistently observed in samples $(118,138,153,180)$

362 were reported by Lohmann (Lohmann et al., 2004) as congeners which concentrations may

363 potentially be influenced by shipboard contamination. It is possible that some PCBs found in the

364 samples were due to shipboard contamination, as PCBs were detected in some field blanks at low

365 levels. However, shipboard contamination would be expected to impact air samples collected 
366 throughout the cruise, and the consistently low levels $(<\mathrm{MDL})$ of PCBs found in the gas phase

367 samples collected throughout the South Atlantic indicates that the measured concentrations are

368 likely representative of actual atmospheric levels with a clear decline from northern to southern

369 latitudes. It should be noted that Oden was built and commissioned 16 years after all uses of PCB

370 were banned in Sweden. As far as has been possible to check among ship documents, no PCB

371 containing equipment has ever been taken aboard. Also, H. Kylin has repeatedly investigated

372 various parts of the ship for contamination of PCB and organochlorine pesticides. This has

373 included screening all batches of paints, etc. used for the ship (particularly those used in the

374 laboratory/sampling areas) prior to application. To date, no sources of contaminants have been

375 identified on board, but there is a risk for contamination with incineration-derived compounds

376 (e.g., HCB) from the industrial activities around the shipyard where Oden is refurbished prior to

377 each expedition.

378 Similar to air samples, PCB118 and PCB153 were most commonly detected PCBs in

379 seawater. However, these analytes also had high MDLs (Table S4) and therefore PCB118 was

380 below MDLs in all samples and PCB153 was below MDLs in all but three samples. PCBs 137,

381 180, and 187 were also detected in several seawater samples and were above MDLs, where

382 concentrations ranged from below MDLs to $2.6 \mathrm{pg} \mathrm{L}^{-1}(\mathrm{PCB} 138)$ at $7^{\circ} \mathrm{N}$. The highest PCB187

383 and PCB180 concentrations $\left(0.50 \mathrm{pg} \mathrm{L}^{-1}\right.$ and $\left.1.1 \mathrm{pg} \mathrm{L}^{-1}\right)$ were also detected in this sample. PCBs

384 in seawater were only detected in the tropics, likely related to the local West Africa source

385 (Gioia et al., 2011). Peak concentrations in seawater PCBs near the equator with very low overall

386 PCB concentrations have also been reported previously in a north-south Atlantic transect,

387 although within the Eastern South Atlantic (Gioia et al., 2008). The only exception was the

388 detection of PCB138 at 78 degrees south $\left(0.98 \mathrm{pg} \mathrm{L}^{-1}\right)$, perhaps influenced by McMurdo Station. 
389 In multiple Antarctic cruises, PCB118 and 153 concentrations ranged from 0.02-0.64 and 0.03-

$390 \quad 0.46 \mathrm{pg} \mathrm{L}^{-1}$, and PCB99/101 had the highest observed concentrations (Galbán-Malagón et al.,

391 2013). PCB concentrations in the Antarctic are decreasing with an apparent half-life of 5.7 years,

392 likely driven by loss to depth via the biological pump (Dachs et al., 2002; Galbán-Malagón et al.,

393 2013).

394

395 Air/Seawater Exchange. The relative concentrations of air and seawater were examined by

396 calculating the water/air fugacity ratios $\left(f_{w} / f_{a}\right)$ as shown below (Mackay and Paterson, 1981):

$$
f_{w} / f_{a}=C_{w} H / C_{a} R T
$$

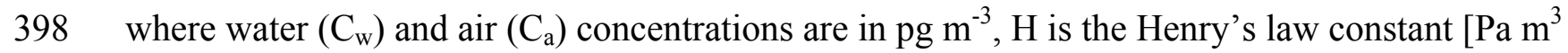

$\left.399 \mathrm{~mole}^{-1}\right], \mathrm{R}$ is the gas constant $\left[8.314 \mathrm{~Pa} \mathrm{~m}^{-3} \mathrm{~K}^{-1} \mathrm{~mole}^{-1}\right]$, and $\mathrm{T}$ is the temperature in $\mathrm{K}$.

400 Calculations were done using average daily air and seawater temperatures measured during

401 individual sample collection and temperature appropriate Henry’s Law constants (Cetin et al., 402 2006; Sahsuvar et al., 2003; Shen and Wania, 2005).

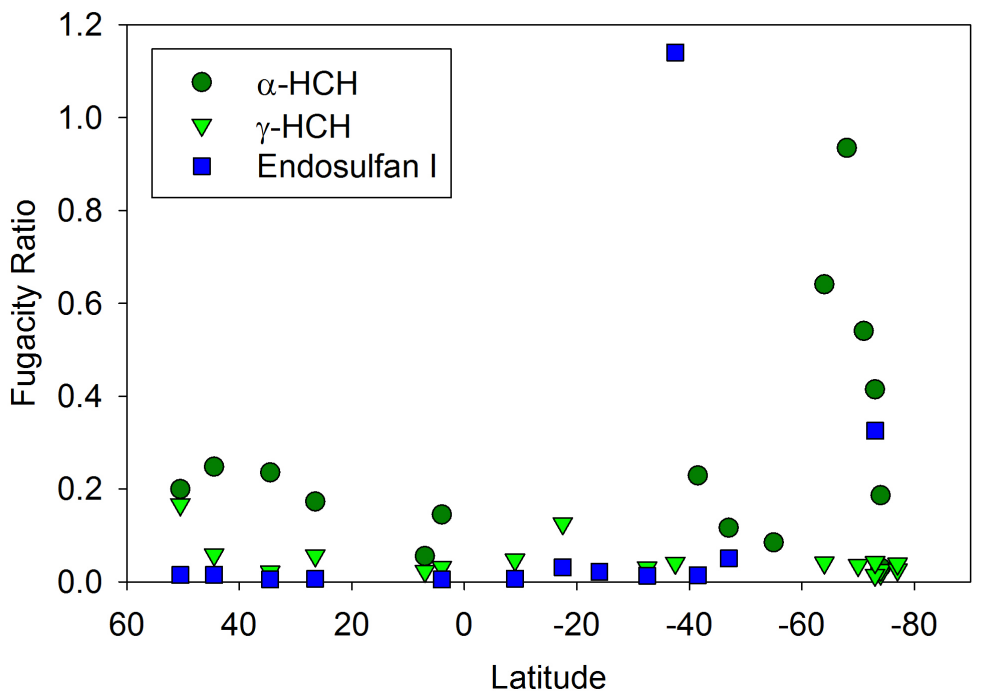

403

404 Figure 4. Fugacity ratios of $\alpha-\mathrm{HCH}, \gamma-\mathrm{HCH}$, and Endosulfan I 
Calculated $\mathrm{HCH}$ fugacity ratios indicated that the Atlantic and Southern Oceans continue

406

407

408

409

410

411

412

413 found to be near equilibrium in the tropical Atlantic, but depositing in the northern and southern

414 Atlantic (Weber et al., 2006). A portion of Southern Ocean samples observed near equilibrium

$415(0.3>\mathrm{F}<3)$ conditions for $\alpha-\mathrm{HCH}$, similar to reports in Arctic Ocean samples (Bruhn et al., 2003; 416 Lohmann et al., 2009). However, a similar trend is not observed for $\gamma$-HCH in the Southern

417 Ocean, consistent with recent observations of net deposition of $\gamma-\mathrm{HCH}$ in the Southern Ocean 418 (Bigot et al., 2016).

to act as a sink for $\alpha$ - and $\gamma-\mathrm{HCH}(\mathrm{F}<1)($ Figure 4, Table S7). Fugacity ratios were not

calculated for some tropical regions as where one or both isomers were below detection in seawater, still supporting continued net deposition in this region. Similarly, a 2008 Atlantic cruise observed consistent $\mathrm{HCH}$ deposition from $45^{\circ} \mathrm{N}$ to $67^{\circ} \mathrm{S}$ (Xie et al., 2011). A 1990-1991 cruise observed net deposition of $\Sigma \mathrm{HCHs}$ in the North Atlantic (Schreitmüller and Ballschmiter, 1995); however a 1999-2000 cruise found that $\Sigma$ HCHs were near air-sea equilibrium in the North Atlantic (Lakaschus et al., 2002). Over a series of Atlantic cruises during the 1990s, $\gamma$-HCH was

The fugacity ratio of Endosulfan indicates net deposition is occurring across the Atlantic, with the exception of the Rio de la Plata sample outlier (Figure 4). Although now being phased out, Endosulfan was still in use during the time of sampling and air concentrations were still relatively high in Endosulfan (Pozo et al., 2009, 2006). Data collected between 1990 and 2004 noted a net deposition of Endosulfan throughout the Atlantic (Lohmann et al., 2009; Weber et al., 2006), and the lack of quantifiable concentrations of Endosulfan in a number of surface seawater samples supports continued deposition from air to water. Fugacity ratios were not calculated for PCBs or HCBs due to the high MDLs in seawater and therefore few gas phase and seawater overlapping data points. Errors associated with these calculated fugacity ratios (Bigot et 
428 al., 2016) were not computed due to a lack of replication in individual air/sea water values.

429 Although the error associated with individual values may be considerable, the consistency across

430 samples gives further support to the conclusions reported of continued net deposition of these

431 POPs.

432 Although previous studies have suggested that the open ocean will move towards being a

433 source of POPs to the atmosphere (Bruhn et al., 2003; Schreitmueller and Ballschmiter, 1995;

434 Weber et al., 2006; Xie et al., 2011), removal of these compounds to the deep ocean bound to

435 particles or organisms, or via the degradative pump (Galbán-Malagón et al., 2012; Goerke et al.,

436 2004; Lohmann et al., 2004; Zhang et al., 2013) may continue to keep surface water

437 concentrations low and indicate net deposition from the atmosphere. Future trends in

438 atmospheric and open ocean concentrations and fluxes of legacy use organochlorines will likely

439 be affected by a number of issues. Changing wind patterns and warming surface water

440 temperatures, as well as new sources of legacy pesticides from melting ice sheets (Cincinelli et

441 al., 2016; Dickhut and Gustafson, 1995; Geisz et al., 2008) all have the potential to alter the

442 predicted decline of phased out POPs. How exactly these physical, chemical, and biological

443 climate change factors will affect this equilibrium has yet to be understood.

\section{Acknowledgements}

446 We sincerely thank the late Rebecca M. Dickhut for her foresight, hard work, friendship

447 and mentorship. The expedition "Oden Southern Ocean 2007-2008" was organized by the

448 Swedish Polar Research Secretariat in cooperation with the United States Antarctic Program. We

449 thank the officers and crew of the R/V Icebreaker Oden, and Heidi Geisz and Elizabeth

450 MacDonald for laboratory assistance. The authors gratefully acknowledge the NOAA Air 
Resources Laboratory (ARL) for the provision of the HYSPLIT transport and dispersion model

and/or READY website (http://www.arl.noaa.gov/ready.php) used in this publication. Thanks to

two reviewers for providing helpful comments. This project was funded by Swedish Research

Council, the National Science Foundation Office of Polar Programs Award 0741379 and NSF

Research Experience for Undergraduates Award 0552612. VIMS contribution XXXX.

\section{References}

Baek, S.-Y., Choi, S.-D., Chang, Y.-S., 2011. Three-Year Atmospheric Monitoring of Organochlorine Pesticides and Polychlorinated Biphenyls in Polar Regions and the South Pacific. Environ. Sci. Technol. 45, 4475-4482. doi:10.1021/es1042996 Bidleman, T.F., Walla, M.D., Roura, R., Carr, E., Schmidt, S., 1993. Organochlorine pesticides in the atmosphere of the Southern Ocean and Antarctica, January-March, 1990. Mar. Pollut. Bull. 26, 258-262.

Bigot, M., Muir, D.C.G., Hawker, D.W., Cropp, R., Dachs, J., Teixeira, C.F., Bengtson Nash, S., 2016. Air-Seawater Exchange of Organochlorine Pesticides in the Southern Ocean between Australia and Antarctica. Environ. Sci. Technol. 50, 8001-8009. doi:10.1021/acs.est.6b01970 Braathen, M., Derocher, A.E., Wiig, Ø., Sørmo, E.G., Lie, E., Skaare, J.U., Jenssen, B.M., 2004. Relationships between PCBs and Thyroid Hormones and Retinol in Female and Male Polar Bears. Environ. Health Perspect. 112, 826-833. doi:10.1289/ehp.6809

\section{Brault, E.K., Goebel, M.E., Geisz, H.N., Canuel, E.A., Dickhut, R.M., 2013. Inter-Annual} Variation of Persistent Organic Pollutants (POPS) in an Antarctic Top Predator Arctocephalus gazella. Environ. Sci. Technol. 47, 12744-12752. doi:10.1021/es403577f

Bruhn, R., Lakaschus, S., McLachlan, M.S., 2003. Air/sea gas exchange of PCBs in the southern Baltic Sea. Atmos. Environ. 37, 3445-3454. doi:10.1016/S1352-2310(03)00329-7

\section{Cabrerizo, A., Dachs, J., Barceló, D., Jones, K.C., 2013. Climatic and Biogeochemical Controls} on the Remobilization and Reservoirs of Persistent Organic Pollutants in Antarctica. Environ. Sci. Technol. 47, 4299-4306. doi:10.1021/es400471c Cetin, B., Ozer, S., Sofuoglu, A., Odabasi, M., 2006. Determination of Henry's law constants of organochlorine pesticides in deionized and saline water as a function of temperature. Atmos.

\section{Environ. 40, 4538-4546. doi:10.1016/j.atmosenv.2006.04.009}

Chiuchiolo, A.L., Dickhut, R.M., Cochran, M.A., Ducklow, H.W., 2004. Persistent Organic

Pollutants at the Base of the Antarctic Marine Food Web. Environ. Sci. Technol. 38, 3551-3557. doi:10.1021/es0351793

Cincinelli, A., Martellini, T., Pozo, K., Kukučka, P., Audy, O., Corsolini, S., 2016. Trematomus bernacchii as an indicator of POP temporal trend in the Antarctic seawaters. Environ. Pollut. 217, 19-25. doi:10.1016/j.envpol.2015.12.057

Dachs, J., Lohmann, R., Ockenden, W.A., Méjanelle, L., Eisenreich, S.J., Jones, K.C., 2002. Oceanic Biogeochemical Controls on Global Dynamics of Persistent Organic Pollutants. Environ. Sci. Technol. 36, 4229-4237. doi:10.1021/es025724k 
Dickhut, R.M., Cincinelli, A., Cochran, M., Ducklow, H.W., 2005. Atmospheric Concentrations and Air-Water Flux of Organochlorine Pesticides along the Western Antarctic Peninsula. Environ. Sci. Technol. 39, 465-470. doi:10.1021/es048648p Dickhut, R.M., Cincinelli, A., Cochran, M., Kylin, H., 2012. Aerosol-Mediated Transport and Deposition of Brominated Diphenyl Ethers to Antarctica. Environ. Sci. Technol. 46, 3135-3140. doi:10.1021/es204375p

Dickhut, R.M., Gustafson, K.E., 1995. Atmospheric inputs of selected polycyclic aromatic hydrocarbons and polychlorinated biphenyls to southern Chesapeake Bay. Mar. Pollut. Bull. 30, 385-396.

Galbán-Malagón, C., Berrojalbiz, N., Ojeda, M.-J., Dachs, J., 2012. The oceanic biological pump modulates the atmospheric transport of persistent organic pollutants to the Arctic. Nat. Commun. 3, 862. doi:10.1038/ncomms 1858

Galbán-Malagón, C., Cabrerizo, A., Caballero, G., Dachs, J., 2013a. Atmospheric occurrence and deposition of hexachlorobenzene and hexachlorocyclohexanes in the Southern Ocean and Antarctic Peninsula. Atmos. Environ. 80, 41-49. doi:10.1016/j.atmosenv.2013.07.061

Galbán-Malagón, C., Del Vento, S., Berrojalbiz, N., Ojeda, M.-J., Dachs, J., 2013 b. Polychlorinated Biphenyls, Hexachlorocyclohexanes and Hexachlorobenzene in Seawater and Phytoplankton from the Southern Ocean (Weddell, South Scotia, and Bellingshausen Seas). Environ. Sci. Technol. 47, 5578-5587. doi:10.1021/es400030q Galbán-Malagón, C., Del Vento, S., Cabrerizo, A., Dachs, J., 2013c. Factors affecting the atmospheric occurrence and deposition of polychlorinated biphenyls in the Southern Ocean. Atmospheric Chem. Phys. 13, 12029-12041. doi:10.5194/acp-13-12029-2013

Geisz, H.N., Dickhut, R.M., Cochran, M.A., Fraser, W.R., Ducklow, H.W., 2008. Melting Glaciers: A Probable Source of DDT to the Antarctic Marine Ecosystem. Environ. Sci. Technol. 42, 3958-3962. doi:10.1021/es702919n

Gioia, R., Eckhardt, S., Breivik, K., Jaward, F.M., Prieto, A., Nizzetto, L., Jones, K.C., 2011. Evidence for Major Emissions of PCBs in the West African Region. Environ. Sci. Technol. 45, 1349-1355. doi:10.1021/es1025239

Gioia, R., Nizzetto, L., Lohmann, R., Dachs, J., Temme, C., Jones, K.C., 2008. Polychlorinated Biphenyls (PCBs) in Air and Seawater of the Atlantic Ocean: Sources, Trends and Processes. Environ. Sci. Technol. 42, 1416-1422. doi:10.1021/es071432d Goerke, H., Weber, K., Bornemann, H., Ramdohr, S., Plötz, J., 2004. Increasing levels and biomagnification of persistent organic pollutants (POPs) in Antarctic biota. Mar. Pollut. Bull. 48, 295-302. doi:10.1016/j.marpolbul.2003.08.004

Harner, T., Kylin, H., Bidleman, T.F., Strachan, W.M.J., 1999. Removal of $\alpha$ - and $\gamma$ Hexachlorocyclohexane and Enantiomers of $\alpha$-Hexachlorocyclohexane in the Eastern Arctic Ocean. Environ. Sci. Technol. 33, 1157-1164. doi:10.1021/es980898g Hunt, L., Bonetto, C., Resh, V.H., Buss, D.F., Fanelli, S., Marrochi, N., Lydy, M.J., 2016. Insecticide concentrations in stream sediments of soy production regions of South America. Sci. Total Environ. 547, 114-124. doi:10.1016/j.scitotenv.2015.12.140 Iwata, H., Tanabe, S., Sakai, N., Tatsukawa, R., 1993. Distribution of persistent organochlorines in the oceanic air and surface seawater and the role of ocean on their global transport and fate. Environ. Sci. Technol. 27, 1080-1098. Jantunen, L.M., Kylin, H., Bidleman, T.F., 2004. Air-water gas exchange of $\alpha$ hexachlorocyclohexane enantiomers in the South Atlantic Ocean and Antarctica. Deep Sea Res. Part II Top. Stud. Oceanogr. 51, 2661-2672. doi:10.1016/j.dsr2.2004.02.002 
536

537

538

539

540

541

542

543

544

545

546

547

548

549

550

551

552

553

554

555

556

557

558

559

560

561

562

563

564

565

566

567

568

569

570

571

572

573

574

575

576

577

578

579

580
Jones, K.C., De Voogt, P., 1999. Persistent organic pollutants (POPs): state of the science. Environ. Pollut. 100, 209-221.

Kallenborn, R., Breivik, K., Eckhardt, S., Lunder, C.R.., Manø, S., Schlabach, M., Stohl, A., 2013. Long-term monitoring of persistent organic pollutants (POPs) at the Norwegian Troll station in Dronning Maud Land, Antarctica. Atmospheric Chem. Phys. Discuss. 13, 6219-6246. doi:10.5194/acpd-13-6219-2013

Lakaschus, S., Weber, K., Wania, F., Bruhn, R., Schrems, O., 2002. The Air-Sea Equilibrium and Time Trend of Hexachlorocyclohexanes in the Atlantic Ocean between the Arctic and Antarctica. Environ. Sci. Technol. 36, 138-145. doi:10.1021/es010211j

Li, Y., Macdonald, R., Ma, J., Hung, H., Venkatesh, S., 2004. Historical $\alpha$-HCH budget in the Arctic Ocean: the Arctic Mass Balance Box Model (AMBBM). Sci. Total Environ. 324, 115139. doi:10.1016/j.scitotenv.2003.10.022

Li, Y.F., Bidleman, T.F., Barrie, L.A., McConnell, L.L., 1998. Global hexachlorocyclohexane use trends and their impact on the arctic atmospheric environment. Geophys. Res. Lett. 25, 3941.

Lohmann, R., Gioia, R., Jones, K.C., Nizzetto, L., Temme, C., Xie, Z., Schulz-Bull, D., Hand, I., Morgan, E., Jantunen, L., 2009. Organochlorine pesticides and PAHs in the surface water and atmosphere of the North Atlantic and Arctic Ocean. Environ. Sci. Technol. 43, 5633-5639. Lohmann, R., Jaward, F.M., Durham, L., Barber, J.L., Ockenden, W., Jones, K.C., Bruhn, R., Lakaschus, S., Dachs, J., Booij, K., 2004. Potential Contamination of Shipboard Air Samples by Diffusive Emissions of PCBs and Other Organic Pollutants: Implications and Solutions. Environ. Sci. Technol. 38, 3965-3970. doi:10.1021/es0350051

Lohmann, R., Klanova, J., Kukucka, P., Yonis, S., Bollinger, K., 2012. PCBs and OCPs on a East-to-West Transect: The Importance of Major Currents and Net Volatilization for PCBs in the Atlantic Ocean. Environ. Sci. Technol. 46, 10471-10479. doi:10.1021/es203459e Mackay, D., Paterson, S., 1981. Calculating fugacity. Environ. Sci. Technol. 15, 1006-1014. Oskam, I., Ropstad, E., Lie, E., Derocher, A., Wiig, Ø., Dahl, E., Larsen, S., Skaare, J.U., 2004. Organochlorines Affect the Steroid Hormone Cortisol in Free-Ranging Polar Bears ( Ursus maritimus ) at Svalbard, Norway. J. Toxicol. Environ. Health A 67, 959-977. doi:10.1080/15287390490443731

Pozo, K., Harner, T., Lee, S.C., Wania, F., Muir, D.C.G., Jones, K.C., 2009. Seasonally Resolved Concentrations of Persistent Organic Pollutants in the Global Atmosphere from the First Year of the GAPS Study. Environ. Sci. Technol. 43, 796-803. doi:10.1021/es802106a Pozo, K., Harner, T., Wania, F., Muir, D.C.G., Jones, K.C., Barrie, L.A., 2006. Toward a Global Network for Persistent Organic Pollutants in Air: Results from the GAPS Study. Environ. Sci. Technol. 40, 4867-4873. doi:10.1021/es060447t

Sahsuvar, L., Helm, P.A., Jantunen, L.M., Bidleman, T.F., 2003. Henry's law constants for $\alpha-$, $\beta$ , and $\gamma$-hexachlorocyclohexanes (HCHs) as a function of temperature and revised estimates of gas exchange in Arctic regions. Atmos. Environ. 37, 983-992. doi:10.1016/S13522310(02)00936-6

Schreitmueller, J., Ballschmiter, K., 1995. Air-water equilibrium of hexachlorocyclohexanes and chloromethoxybenzenes in the North and South Atlantic. Environ. Sci. Technol. 29, 207-215. Shen, L., Wania, F., 2005. Compilation, Evaluation, and Selection of Physical-Chemical Property Data for Organochlorine Pesticides. J. Chem. Eng. Data 50, 742-768. doi:10.1021/je049693f 
581 Sonne, C., 2010. Health effects from long-range transported contaminants in Arctic top 582 predators: An integrated review based on studies of polar bears and relevant model species.

583 Environ. Int. 36, 461-491. doi:10.1016/j.envint.2010.03.002

584 Stein, A.F., Draxler, R.R., Rolph, G.D., Stunder, B.J.B., Cohen, M.D., Ngan, F., 2015. NOAA's 585 HYSPLIT Atmospheric Transport and Dispersion Modeling System. Bull. Am. Meteorol. Soc. 586 96, 2059-2077. doi:10.1175/BAMS-D-14-00110.1

587 Tanabe, S., Hidaka, H., Tatsukawa, R., 1983. PCBs and Chlorinated Hydrocarbon Pesticides in 588 Antarctic Atmosphere and Hydrosphere. Chemosphere 12, 277-288.

589 UNEP, 2016. pops.int [WWW Document]. Stockh. Conv. Persistent Org. Pollut. URL 590 http://www.pops.int (accessed 11.2.16).

591 Walker, K., Vallero, D.A., Lewis, R.G., 1999. Factors Influencing the Distribution of Lindane 592 and Other Hexachlorocyclohexanes in the Environment. Environ. Sci. Technol. 33, 4373-4378. 593 doi:10.1021/es990647n

594 Wania, F., Mackay, D., 1996. Tracking the distribution of persistent organic pollutants. Environ. 595 Sci. Technol. 30, 390A-396A.

596 Weber, J., Halsall, C.J., Muir, D., Teixeira, C., Small, J., Solomon, K., Hermanson, M., Hung, 597 H., Bidleman, T., 2010. Endosulfan, a global pesticide: A review of its fate in the environment 598 and occurrence in the Arctic. Sci. Total Environ. 408, 2966-2984.

599 doi:10.1016/j.scitotenv.2009.10.077

600 Weber, J., Halsall, C.J., Muir, D.C.G., Teixeira, C., Burniston, D.A., Strachan, W.M.J., Hung, 601 H., Mackay, N., Arnold, D., Kylin, H., 2006. Endosulfan and $\gamma-\mathrm{HCH}$ in the Arctic: An

602 Assessment of Surface Seawater Concentrations and Air-Sea Exchange. Environ. Sci. Technol. 603 40, 7570-7576. doi:10.1021/es061591h

604 Xie, Z., Koch, B.P., Möller, A., Sturm, R., Ebinghaus, R., 2011. Transport and fate of 605 hexachlorocyclohexanes in the oceanic air and surface seawater. Biogeosciences 8, 2621-2633. 606 doi:10.5194/bg-8-2621-2011

607 Zhang, L., Dickhut, R., DeMaster, D., Pohl, K., Lohmann, R., 2013. Organochlorine Pollutants 608 in Western Antarctic Peninsula Sediments and Benthic Deposit Feeders. Environ. Sci. Technol. 609 47, 5643-5651. doi:10.1021/es303553h

610 Zhang, L., Lohmann, R., 2010. Cycling of PCBs and HCB in the Surface Ocean-Lower

611 Atmosphere of the Open Pacific. Environ. Sci. Technol. 44, 3832-3838. doi:10.1021/es9039852 